\title{
Effect of 7E Model Inquiry-Based Approach on Student Achievement
}

\author{
Nilda V. San Miguel \\ nildssanmiguel@gmail.com \\ Department of Education, Lumban District, Laguna, Philippines, 4014
}

\begin{abstract}
When the structure of knowledge and learning process is examined in education as well as in science, it will be seen that the current teaching and learning models are not enough and therefore they have to be improved or other models are required. This was shown in this study, how the 7E MODEL INQUIRY-BASED APPROACH affects the students' achievement. Seventy learners from Masapang Elementary School were the center of this research. Two classes from the Grade which were group heterogeneously as the respondents in questionnaire and the classes that undergo traditional instruction approach and 7E Model Inquiry-Based approach in teaching Science. The results were based from the spot tests given by the researcher. The teacher applied the traditional instruction approach in one class while the other was the application of 7E Model Inquiry-Based approach. Female Reproductive System as the topic in Science. This study employed the experimental design in research. Calderon and Gonzales (1993) stated that in this design, there are two or more experimental variables to be tested. This study revealed that there is a significant difference between the academic achievement of learners who had undergone traditional instruction approach and academic achievement of learners who had undergone 7E model inquiry-based approach. The students performed better when 7E model inquiry-based approach is used rather than traditional instruction approach. It was found out that students understand subjects easier if they experience-live them and associate this information more accurately with events they encounter in everyday life. By applying the inquiry based teaching method; learners developed their critical thinking skills. It is recommended for instructors to make use of 7E model inquiry-based approach more than traditional instruction approach. Though this would take more effort to do, it would give better academic achievement for learners.
\end{abstract}

Keywords: elicit; engage; explore; explain; elaborate; evaluate; extend; inquiry

\section{Introduction}

Education is the process of transferring knowledge to the next generation. It is also preserving information so that the future generation can still benefit from the patience and determination of the past.

This is the reason why the Department of Education (Dep Ed) is continually improving the curriculum. From BEC Curriculum, to RBEC, then the Understanding by Design (UBD), and the K to 12 program.

This $\mathrm{K}$ to 12 program has six key characteristics such as strengthening early childhood education, making the curriculum relevant to learners, building skills, ensuring unified and seamless learning, gearing up for the future and nurturing the fully developed Filipino. To ensure the achievement of the following features the Department of Education is thoroughly characterized by various structures and strategies both compared to local and international standard. The used of different teaching approaches or strategies in teaching. One of the approaches being encouraged to be used by the teachers in teaching science is the 7Es. Would this strategy be an effective way so that students would easily grasp the concepts and connected ideas to a certain topic? 
This is the focus of this study.

\subsection{Background of the Study}

The guidelines being discussed in DepEd Order No. 42. Series of 2016 is to support teachers in organizing and managing their classes and lessons effectively and efficiently and to ensure the achievement of learning outcomes.

In this regard, strategy like 7Es approach to be applied in teaching Science has taken into consideration to effectively cater the needs of the learners.

The respondents of this study are 70 grade five students of Masapang Elementary School. The topics in this subject follow the topics as line-up by DepEd under the $\mathrm{K}$ to 12 program. It includes the system of the human bodies, taking care of health, healthy foods, the ecosystem, plants and animals, our environment, and the universe.

To learn these topics, the teacher implements many strategies: experimentation, group activities, lecture method, exploratory activity, investigative projects, and 7Es pedagogical approach.

How is the 7Es pedagogical approach in terms of the output in the exams and quizzes of these grade five students? Are they learning much in the same level or degree that they learn using the lecture type method or the typical traditional instruction method? These are the questions that the researcher has in mind in the beginning of the study.

\subsection{Theoretical Framework}

The 7E instructional model is a common learning cycle used by science teachers. Earlier known the 5E model, the 7E model is an extension of its predecessor that has been expanded to ensure teachers don't leave out any essential instructional components. The 7E model is also often used as a conceptual change model. Within its levels teachers can work from eliciting dissatisfaction at the beginning to having students extend their new understanding to ensure the misunderstanding has been usurped. As you learn about the 7E model think of how the lesson we watched on heat fits into the model as well as the lesson you developed in the previous unit. It is also helpful to think of units you currently use in class and how the 7E model fits into their instruction.

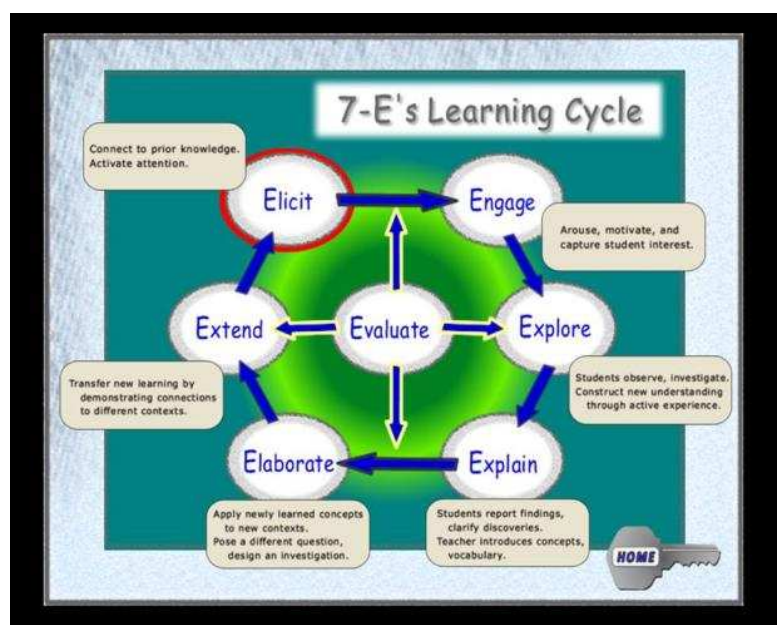

Fig. 1. The 7E model of inquiry-based approach 
Research on how people learn and the incorporation of that research into lesson plans and curriculum development demands that the $5 \mathrm{E}$ model be expanded to a 7E model.

7E's Learning Cycle is featured by a lot of advantages that help learners acquire concepts and apply them in new contexts and real situations, it also develops the students' skills of scientific research, improves their problem solving abilities, develops their skills of dialogue and team work spirit, in addition it helps them amend their wrong visions on the previous mathematical concepts related to the lesson topic, (Kalayci, 2005). The 7E's learning cycle strategy includes the following seven stages (Akerson, 2009):

1. Excitement: This stage aims at motivating learners and enhancing their curiosity for learning the concept. Teacher motivates his students and creates the element of curiosity among them and encourages prediction.

2. Exploration: This stage aims at satisfying the learners' curiosity through providing them with necessary experiences and aid, in order to enable them to acquire the meaning of the concept. Teacher in this stage designs activities that enable learners to recognize the concept structure, and will be responsible for providing sufficient and clear instructions and suitable tools related to each activity, giving them the opportunity to work in groups to practice investigation. This stage leads to enhance students intellectually, that is, due to the variety of new well-designed activities it contains, and so the student's cognitive balance is disturbed, and this motivates him to ask questions and seeking answers, that he cannot answer, and then reach primary conclusions about the concept, discovering new ideas or relationships which were not recognized for him before.

3. Explanation: This stage aims at explaining the concept as well as the terms. In this stage, teacher directs his students towards the concept construction and identifying it in a cooperative manner through emphasizing on certain sides of the activities that they practiced in the exploration stage. To achieve that, teacher collects the information that his students gathered in the exploration stage and helps them organize and process these information, providing them with the necessary explanations that help them organize their exploratory experiences in its correct position and put them in order to identify the concept. This stage helps the student recover his cognitive balance, in accordance with the concept of matching which was talked about by Beige in his theory about the cognitive development.

4. Expansion: It is also called the application stage, aiming at the discovery of new applications for the concept, in this stage learners use their acquired experiences about the concept and apply it in new situations and problems so as to expand their comprehension of such experiences, leading into a deeper understanding of the concept. Teacher at this stage will focus his efforts to expand the students' understanding by providing more related examples on this concept.

5. Extension: This stage aims at clarifying the relationship of the concept with other concepts, in which the teacher helps his student recognize how the concept relates with other concepts, through asking questions that help them discover such relationships.

6. Exchanging: This stage aims at exchanging experiences and ideas or changing them, where the teacher encourages the students' cooperation and participation through well-designed activities and exchanging experiences.

7. Evaluation: Teacher in this stage evaluates his students' learning of the concept and provides them with the suitable feedback, that is, through putting them in new situations and dealing with new problems. Evaluation process may be carried out through each stage of the learning cycle stages instead of the final stage only.

\subsection{Conceptual Framework}

The figure on the next page shows the independent and dependent variables for this study. The two teaching styles to be investigated are traditional instruction approach and the application of 7E Model InquiryBased approach. They are part of the independent variables. The academic achievement of the grade five learners is part of the dependent variable. These two groups of variables are connected with an arrow to signify effect of style of teaching. 
Teaching Tool in Science

- Traditional Instruction Approach

- $\quad$ 7E Model Inquiry-Based Approach

Academic Achievement of Grade Five Pupils

Fig. 1. The research paradigm

\subsection{Hypothesis}

There is no significant difference between the academic achievement of the learners using traditional instruction approach and 7E Model Inquiry-Based approach in teaching Science.

\subsection{Statement of the Problem}

This study seeks to determine the effect of 7E Model Inquiry-Based approach in teaching Science to the academic achievement of grade five learners in Masapang Elementary School.

Specifically, it sought to determine the answer to the following questions:

1.) What is the status of the teacher's use of different tools in Science in terms of the ff:

a.) Traditional instruction approach;

b.) 7E Model Inquiry-Based approach;

2.) What is the mean level of the academic achievement of the learners using the two approaches in teaching Science? and

3.) Is there a significant difference between the academic achievement of the learners using the two teaching tools in teaching Science?

\subsection{Significance of the Study}

Through the study, the following persons or groups of persons will be benefitted:

- Students - Academic achievement can be associated to the teaching approach that the teacher is implementing. When the proper approach is used, the difficulty in understanding is minimized and retention of learning becomes longer or even permanent.

- Teachers - Knowing the approach that will greatly help students will diminish the difficulty of the teachers in assisting the learners towards higher academic achievement.

- School Heads - Leading the school is not that easy. It sometimes requires motivation from school heads so that teachers and students will always be on the goal of attaining new knowledge and wisdom. If proper approach in teaching is dealt by school heads, then, motivation on the use of that approach will greatly help in attaining better school standing.

- Parents - Every parents long to have their kids a good standing in terms of academic. Ourselves is our greatest enemy, and so, if the weakness of every person in learning is dealt with, then parents will not have problems on low grades of their kids. 


\subsection{Scope and Limitation}

This study will make use of the grade five students of Masapang Elementary School as the respondents in questionnaire and the classes who will undergo traditional instruction approach and 7E Model Inquiry-Based approach in teaching Science. The results will be based from the spot tests given to the two heterogeneous grade 5 classes. The teacher will be applying the traditional instruction approach in one class while the other is the application of 7E Model Inquiry-Based approach. Female Reproductive System as the topic in Science. The small time allotted to the researcher is a factor to be considered in looking at the conclusion, that means, the conclusion or result may not be conclusive for all grade five learners in the district of Victoria, Laguna.

\section{Related Readings}

This section cites related readings to the present study. They will give light to the different issues or variables concerned to the focus of this study.

In the study of Vick (2018) he found out the effects of 7E Model inquiry labs in Advanced Placement (AP) Physics on students' performance on AP exam inquiry lab-based questions. The study, which is described in detail, employed a one group, pretest-posttest design to answer the research question regarding the effects of the inquiry-based AP Physics labs on students' achievement on AP exam inquiry lab questions as measured by unit assessments. Data collection and analysis strategies are also discussed. Sources of data included a pretest, lab reports, and a posttest. The data were analyzed using descriptive statistics, specifically a t-test comparison of pretest and posttest results. Reflection upon the data and formation of an action plan after its analysis were the last steps in the action research process. Through this process, it was demonstrated that the 7E Model inquiry labs did have a positive effect on student achievement on AP inquiry lab questions.

In science education, action research has been conducted at many levels for the purpose of "advancing knowledge about how science teachers teach and what students learn in science" (Capobianco \& Feldman, 2010, p. 911). Capobianco and Feldman (2010) argued that action research in the science classroom can serve as a way for science teachers to maintain a capacity for change; they must adjust to ongoing changes in education, and action research can serve as a mean to address and embrace these changes. In the context of the evolving AP science curriculum, this teacher-researcher aimed to use action research as a means to investigate changes in her current classroom and lab practices, since the action research study of 7E Model inquiry labs in her own classroom had the potential to enhance instructional practices for her students.

Most of the research on the effectiveness of the 7E Model has been conducted in Turkey, which adopted a constructivist approach to science curriculum development and education in 2005 (Balta \& Sarac, 2016). The current action research study therefore serves to increase understanding of the effect of the 7E model on U.S. students. Further, many of the Turkish studies (Duran \& Duran, 2004; Acisil \& Turgut, 2011) involved only the 5E (as opposed to 7E) Model with the inquiry labs. The action research, therefore, offered to the teacher-researcher the opportunity to improve her classroom practice by gaining more insight into 7E Model inquiry labs and facilitating scientific communication.

Turgut et al (2012) developed worksheets in order to ensure conceptual change and development based on experimental activities, these were prepared and administrated in accordance with 7E model. In the research, 6 students with high level, moderate level and low level of conceptual changes were interviewed about their achievements. The activities and materials, which were applied according to the average scores of students, were found to be effective on conceptual development and eliminating existing misconceptions of students about the subject of electromagnetism.

The results of studies conducted by Gunes et al., (2011) on learning, teaching and science education, the nature of physics and subjects of physics highlights the use of some methods while teaching subjects of physics. In order to have a meaningful and permanent learning in physics classes, the most efficient 
approaches including activities aiming conceptual development, based on the context in which they encounter in real life, with validity of the initial information is checked, require students to be mentally and physically active, emphasize the importance of quick feedbacks with team work in laboratories and classroom activities should be used. In this context, it is very important to select the most appropriate teaching method or methods in order to allow them to configure the achievements of physics class in a meaningful way and use these achievements in the necessary environments. What to teach, how to teach and how to perform evaluation are the main questions that need to be asked together to teach a course. Therefore, the curriculum, course materials, books, methods and techniques must be able to ensure the realization of meaningful learning for students.

According to Turgur, et.al. (2016) it is very well-known that students understand subjects easier if they experience-live them and associate this information more accurately with events they encounter in everyday life. Examples from real life and associating the subject with daily life will help students to be more willing to participate in the science and physics classes, in which they normally feel nervous. The inquiry and research-based teaching methods developed by taking the steps followed in the scientific research process into account (discovery, exploration and critical research method) and conceptual change based teaching methods (conceptual change texts, analogies, 5E and 7E models) seem to be more prominent teaching methods compared to other methods. The use of these methods a little more than others will allow students to have more regular conceptual frameworks and skills and have a better learning of the subjects of physics (Acisli 2010; Gurbuz 2012; Hurca 2008; Kanl1 2007; Savas 2009 and Ozsevgec 2006).

Fitmur (2018) showed that the 7E learning model can improve the scientific literacy of elementary students. The research method used in this study is a quasi - experiment, one group pre-test post-test. The results of the pre-test and post-test showed a significant increase. These results indicate that the $7 \mathrm{E}$ learning model can improve the scientific literacy of elementary students.

Iskandar (2005) discussed in his study that Learning Cycle 7E model is a learner-centered model. This model consists of stages of activities organized in such a way that students can master the competencies that must be achieved in learning by playing an active role. These stages are elicited, engage, explore, explain, elaborate, evaluate, and extend. Learning Cycle 7E models have several advantages, including: stimulating students to remember the subject matter they have learned before, motivating students to be more effective and increasing students' curiosity, training students to learn to do concepts through experimental activities, train students to convey verbally the concepts they have learned, provide opportunities for students to think, search, find, and explain examples of the application of the concepts they have learned. Learning Cycle $7 \mathrm{E}$ model with seven learning steps is expected to be able to improve the scientific literacy component that has been established by PISA, namely: knowing scientific questions can be improved at the elicit and engage stages, identifying the evidence needed in scientific investigation can be improved in the explore, draw and evaluate conclusions, and communicating valid conclusions can be increased at the explain stage, assessing the accuracy of the answers can be improved in the evaluation stage, and demonstrating an understanding of scientific concepts can be improved in the elaborate and extend stages.

Previous research shows the effectiveness of a learning model, namely the 7E learning cycle model is very effective applied to pure science. Research conducted show that the application of the 7E Learning Cycle model can improve student learning outcomes and generic science skills, Apriyani (2010).

Imaza (2010) gave a positive impression on $7 \mathrm{E}$ model learning model to participants educated in the experimental group to reduce misconceptions and prove that the $7 \mathrm{E}$ model is effective learning. Learning Cycle 7E learning models suggest that the learning process can involve students in active learning activities so that the process of assimilation, accommodation, and organization in the cognitive structure of students is achieved. If there is a good knowledge construction process, students will be able to increase their understanding of the material being studied.

In the study made by Nuri (2016), he confirmed that 7E learning cycle have a positive effect on students' achievement. He also discussed the effect of 7E was not significant for school level, type of 
publication and duration. However, regarding the subject matter a significant difference was observed. The high effect size calculated in this meta-analysis implies that the $7 \mathrm{E}$ learning cycle is a useful strategy that should be included in science curriculums.

Ozalp (2016), In his research proposed learning cycles in the literature are a consequence of constructivist learning theory which basically asserts that students construct their own knowledge. Learning cycles enables teachers to conduct a series of activities that are meaningful for students and help students to practice for their critical thinking skills. By using the learning cycle students can learn science concepts, fix their incorrect or incomplete knowledge, learn the concepts profoundly, and adapt the learnings gained in school to their daily life

Özbek, Çelik, Ulukök \& Sarı, (2012) encouraged the use of constructivist learning cycle models in science teaching furnishes content of the courses, increases students' attention towards courses, ensures permanent learning, changes students' prejudgments towards science and make courses more entertaining and fruitful.

Bubul (2010), in his study mentioned that there are different forms of inquiry learning. In structured inquiry the teacher provides the input for the student with a problem to investigate along with the procedures and materials. This type of inquiry learning is used to teach a specific concept, fact or skill and leads the way to open inquiry where the student formulates his own problem to investigate. An example of a structured inquiry learning approach is the Learning Inquiry Cycle Model, based on Piagets theory of cognitive learning (Bevevino, Dengel, \& Adams, 1999). The learning cycle model is a teaching procedure consistent with the inquiry nature of science and with the way children naturally learn (Cavallo \& Laubach, 2001). Many versions of the learning cycle appear in science curricula with phases ranging in number from $4 \mathrm{E}$ to $5 \mathrm{E}$ to $7 \mathrm{E}$. Regardless of the quantity of phases, every learning cycle has at its core the same purpose.

\section{Inquiry vs. Traditional Labs}

Inquiry labs are designed to increase students' involvement and their development of critical thinking and problem-solving skills (College Board, 2015). Labs can be seen on a continuum ranging from teacher-structured to guide to student-directed, open inquiries (Chang, Chen, Guo, Cheng, Lin, \& Jen, 2011). At one end of this spectrum, confirmation inquiry is closest to a traditional lab method, since the teacher provides students with a question and method for answering it (Bianchi \& Bell, 2008), so they usually know the answer in advance. A structured inquiry lab, by contrast, asks students to generate an explanation supported by evidence gathered based on a question and procedure developed by the teacher (Bianchi \& Bell, 2008). Moving further toward the student-directed end of the spectrum, teachers may only provide students with a question for which they then develop a procedure to answer in guided inquiry (Bianchi \& Bell, 2008). Most of the 7E Model labs in the present action research study were rooted in guided inquiry. At the furthest end of the spectrum is open inquiry, in which students develop both the question and procedure (Bianchi \& Bell, 2008). Advanced Placement (AP) Physics inquiry labs naturally focus on the part of the continuum between guided inquiries and student-directed, open inquiries (College Board, 2015). In labs anywhere on the continuum, the teacher acts more as a facilitator than as a provider of direct instruction (Chang et al., 2011). Inquiry labs allow students and teachers to work together in an environment resembling a true scientific community. Constructivist principles are evident in inquiry labs because students solve higher-order thinking problems that lead them to create their own knowledge, with the teacher serving as a guide (Chang et al., 2011). As students become more experienced with inquiry labs, they can be expected to develop more refined reasoning methods (College Board, 2015).

According to Chang et al. (2011), to show true proficiency in inquiry, a student should be able to :

- ask questions and/or create a hypothesis based on experience or given evidence;

- use available resources to develop a method to answer the question or confirm the hypothesis;

- collect data with correct instruments using the developed plan; and

- analyze and interpret data to form logical conclusions.

Instructors can easily assess a student's competence during inquiry labs and their ability to complete 
similar inquiry tasks in the future based on these four criteria (Chang et al., 2011). Using a posttest-only, control group design involving 20 physical science classes in a large, urban, inner-city comprehensive high school over a period of 36 weeks, Freedman (1997) found that participation in science laboratories improved the attitudes of students - who in that study were of various races and ethnicities - toward science and the acquisition of scientific knowledge. The use of inquiry labs instead of traditional labs has been associated with improvements in three areas, namely statements of experimental procedures, lab write-ups, and data analysis and interpretation (Szott, 2014). In a study of his own eleventh- and twelfth-grade physics students at a high school in Alberta, Canada,

Szott (2014) observed that open-ended laboratory activities gave students opportunities to design experiments, make models based on data, and work collaboratively with peers. Likewise, a study of 62 high school chemistry students in a large, urban public high school in Turkey by Acar Sesen and Tarhan (2013) found that students participating in inquiry labs tended to have fewer misconceptions about the topic of study (in this case, electrochemistry) than those who participated in traditional labs. Students' procedures also became more descriptive after participation in several inquiry labs (Szott, 2014). To enhance the students' procedures and ensure the correct usage of unfamiliar science terminology, on the other hand, direct instruction was found to be needed in scientific vocabulary and report-writing skills (Szott, 2014). Blanchard, Southerland, Osborne, Sampson, and Annetta (2010), in a study of 1,700 students in 12 middle schools and 12 high schools designed to assess the effectiveness of guided inquiry during a one-week forensics unit, found that those who participated in this form of learning increased their procedural knowledge more than those who participated in traditional laboratory activities that were solely teacher-directed. Students participating in an inquiry lab also often collect more data than those participating in a traditional lab. Thus Szott (2014) found that the former, having had more time and freedom to explore during the physics labs, made insightful observations that may have been overlooked in a traditional lab. Again, as with the procedures, guidance from instructors and practice writing reports was found to be necessary for students to become proficient. The purpose of inquiry labs is not for students to obtain correct answers, but to interpret and analyze their results.

Students beginning an inquiry lab may feel overwhelmed by having to develop their own procedures (Szott, 2014). However, as Acar Sesen and Tarhan (2013) found, their attitudes toward a subject and laboratory work in general may improve with the completion of several inquiry labs; traditionally-taught students, by contrast, showed no significant change in attitude over multiple labs. Also, Szott (2014) found that students in his class appeared more engaged in the activities than they had during a traditional lab.

Blanchard et al. (2010) likewise found that guided inquiry could benefit students in high poverty schools by promoting a positive attitude toward science. Inquiry experiments take no longer to complete than traditional labs (Szott, 2014). A sticking point is often that teachers must be willing to let go of some control in order to conduct them. At the same time, students require support and encouragement throughout the process, for instance by being allowed to rewrite insufficient lab reports (Szott, 2014).

In the research conducted by Bybee et al., (2006), 5E learning cycle instruction model was used. It requires the instruction of five discrete elements: (a) Engagement: The teacher or a curriculum task accesses the learners' prior knowledge and helps them become engaged in a new concept through the use of short activities that promote curiosity and elicit prior knowledge. (b)Exploration: Exploration experiences provide students with a common base of activities within which current concepts (particularly misconceptions), processes, and skills are identified and conceptual change is facilitated. (c)Explanation: The explanation phase focuses students' attention on a particular aspect of their engagement and exploration experiences and provides opportunities to demonstrate their conceptual understanding, process skills, or behaviors. This phase also provides opportunities for teachers to directly introduce a concept, process, or skill. (d)Elaboration: After receiving explanations about main ideas and terms for their learning tasks, it is important to involve the students in further experiences that extend, or elaborate, the concepts, processes, or skills. This elaboration phase facilitates the transfer of concepts to closely related but new situations. In some cases, students may still have misconceptions, or they may only understand a concept in terms of the exploratory experience. (e) 
Evaluation: This is the important opportunity for students to use the skills they have acquired and evaluate their understanding. In addition, the students should receive feedback on the adequacy of their explanations. Informal evaluation can occur at the beginning and throughout the $5 \mathrm{E}$ sequence. The teacher can complete a formal evaluation after the elaboration phase. This is the phase in which teachers administer assessments to determine each students level of understanding (Bybee et al., 2006)

The inquiry-based teaching approach is supported on knowledge about the learning process that has emerged from research (Bransford, Brown, \& Cocking, 2000). In inquiry-based science education, children become engaged in many of the activities and thinking processes that scientists use to produce new knowledge. Science educators encourage teachers to replace traditional teacher-centered instructional practices, such as emphasis on textbooks, lectures, and scientific facts, with inquiry-oriented approaches that (a) engage student interest in science, (b) provide opportunities for students to use appropriate laboratory techniques to collect evidence, (c) require students to solve problems using logic and evidence, (d) encourage students to conduct further study to develop more elaborate explanations, and (e) emphasize the importance of writing scientific explanations on the basis of evidence(secker,2002). Sandoval \& Reiser (2004) pointed out in order to build the inquiry-based classroom environment must construct a community of practice like the scientists work. In authentic inquiry-based activities, the students take action as scientists did, experiencing the process of knowing and the justification of knowledge. In contrast, the traditional classroom often looks like a one-person show with a largely uninvolved learner. Traditional classes are usually dominated by direct and unilateral instruction. Traditional approach followers assume that there is a fixed body of knowledge that the student must come to know. Students are expected to blindly accept the information they are given without questioning the instructor (Stofflett, 1998). The teacher seeks to transfer thoughts and meanings to the passive student leaving little room for student-initiated questions, independent thought or interaction between students. Even the in activities based subjects, although activities are done in a group but do not encourage discussion or exploration of the concepts involved. This tends to overlook the critical thinking and unifying concepts essential to true science literacy and appreciation (Yore, 2001). This teacher-centered method of teaching also assumes that all students have the same level of background knowledge in the subject matter and are able to absorb the material at the same pace (Lord, 1999).

\section{Research Design and Methodology}

\subsection{Research Design}

This study employed the experimental design in research. Calderon and Gonzales (1993) stated that in this design, there are two or more experimental variables to be tested. So for this study, two classes were equal to the number of experimental variables, namely, traditional instruction approach and 7E Model Inquiry-Based approach. Each teaching approach was applied on the group to which it is assigned. All other variables were kept equal in all the groups. After the experimental period, result from their spot test will be recorded. The teaching approach assigned to the group with the higher mean score was considered more effective than the teaching approach assigned to the group with lower mean score.

\subsection{Respondents}

The respondents of this study are the grade 5 learners of Masapang Elementary School. It comprises of 70 pupils from two selected grade 5 classes. This study was conducted school year 2019-2020.

\subsection{Data Gathering Procedure}


This data will make use of quantitative data and qualitative data. The sources are the result of survey and spot tests of the learners. To specify, here is the plan for every item in the Statement of the Problem (SOP).

To answer ethical concerns that have direct and indirect relation to the present study, the seven-point ethical issues are answered here:

i. Social value - The relationship and social value is protected since the method to be used is giving of spot tests after the lesson. The element of surprise is avoided. Teachers are expecting, and therefore ready for the principal's visit.

ii. Scientific validity - The researcher asked the help of an expert to scientifically treat the data using statistical treatment fitted for the data gathered. Scientific validity will be attained because there will be no jumping into conclusion that will happen. Only conclusion which was backed up with results of treatment were presented in this research.

iii. Fair subject selection - The learners came from the two heterogeneous classes. There were no emotional or relational biases. The selection was purely professional.

iv. Favorable risk-benefit ratio - Both the teacher and the learners were benefitted in this study. Risk was not a permeating factor because the giving of spot test was one of the monitoring scheme done by the school heads to monitor learners' achievement and teacher's effectiveness.

v. Independent review - Analysis and interpretation of data were carefully done. Only the plain data of responses treated.

vi. Informed consent - Teachers were informed beforehand that spot tests would be given after they had delivered the lessons. The data would come from the result of the given spot test.

vii. Respect for enrolled subject - Name of learners and Science teachers were not revealed here because the focus was the achievement of learners.

\subsection{Data-Gathering Instruments}

To answer statements of the problem, the following instruments were used:

For statement of the problem number 1, a survey questions on teacher's traditional instruction (Appendix A) consisting of 12 items, and 7E model inquiry-based approach (Appendix B) consisting of 12 items were used. Both of them made use of the following scales for students to evaluate base on their perception about their teacher in Science.

5 - Very highly describes my teacher

4 - Highly describes my teacher

3 - Sometimes describes my teacher

2 - Seldom describes my teacher

1 - Does not describe my teacher

For statement of the problem number 2, a 15 -item spot test was prepared by the researcher. The items in the spot test covered the topic that was discussed using the two approaches in teaching.

\subsection{Statistical Tools}

The statistical treatments will be used for this study:

For statement of the problem number 1 and 2, mean and standard deviation were used to measure students' perception on teacher's teaching approach and the academic achievement of the students in terms of their quiz.

For statement of the problem number 3, t-test for two sample means was used. The formula is given below: 


$$
t=\frac{\bar{x}_{1}-\bar{x}_{2}}{\sqrt{\frac{s_{1}^{2}}{n_{1}}+\frac{s_{2}^{2}}{n_{2}}}}
$$

\section{$\bar{x}_{1}:$ Mean value of the first group \\ $\bar{x}_{2}:$ Mean value of the second group \\ $n_{1}$ : Size of the first group \\ $n_{2}:$ Size of the second group \\ $s_{1}:$ Standard deviation of the first group \\ $s_{2}:$ Standard deviation of the second group}

\section{Presentation, Analysis and Interpretation of Data}

This section lay out the result of the study in tabular forms. All questions in the statement of the problem are carefully answered through the presentation, analysis and interpretation of the results.

\subsection{Status of Traditional Instruction Approach}

The table on the next page shows the teacher's status on the use of traditional instruction approach as a teaching methodology.

The twelve items all corresponds to the rate of the science teacher as perceived by the seventy students who have undergone this teacher's traditional instruction approach while they learn the topic in Science which is Female Reproductive System of the body. The twelve items deal with teacher's preparation (item 1), simplicity of the tool (item 2), visibility of the tool (item 3), readability of the tool (item 4), limiting number of fonts used in the tool (item 5), use of color in the tool (item 6), non-use of chalkboard (item 7), proper placement of teaching tool (item 8), non-passing of teaching tool to learners (item 9), proper timing of display of tools (item 10), talking to students and not to teaching tool (item 11), and clear explanation of what is written in the teaching tool (item 12).

All items received an outstanding rating. Overall, the teacher receives an outstanding rating (4.47) which means that the teacher is preparing and executing well her task through the use of this teaching tool. The standard deviation of 0.48 shows that the rating of the students is homogenous.

Table 1. The teacher's status using the traditional instruction approach teaching approach

\begin{tabular}{|l|c|c|c|}
\hline \multicolumn{1}{|c|}{ Items } & Mean & SD & Interpretation \\
\hline 1. Prepare outlines in advance & 4.31 & 0.48 & Outstanding \\
\hline 2. Keep outlines simple & 4.29 & 0.48 & Outstanding \\
\hline 3. Make sure outlines are large enough & 4.69 & 0.47 & Outstanding \\
\hline 4. Use fonts that are easy to read & 4.33 & 0.48 & Outstanding \\
\hline 5. Use a limited number of fonts & 4.28 & 0.48 & Outstanding \\
\hline 6. Use color effectively & 4.39 & 0.48 & Outstanding \\
\hline 7. Avoid using the chalkboard & 4.56 & 0.48 & Outstanding \\
\hline $\begin{array}{l}\text { 8. Display outlines where listeners can } \\
\text { see them }\end{array}$ & 4.76 & 0.47 & Outstanding \\
\hline $\begin{array}{l}\text { 9. Avoid passing outlines among the } \\
\text { audience }\end{array}$ & 4.35 & 0.48 & \\
\hline
\end{tabular}




\begin{tabular}{|c|c|c|c|}
\hline $\begin{array}{l}\text { 10. Display outlines only while } \\
\text { discussing them }\end{array}$ & 4.59 & 0.48 & Outstanding \\
\hline $\begin{array}{l}\text { 11. Talk to her audience, not to her } \\
\text { outlines }\end{array}$ & 4.39 & 0.48 & Outstanding \\
\hline Average & 4.47 & 0.48 & Outstanding \\
\hline $\begin{array}{ll}\text { 4.21-5.00 } & \text { Outstanding } \\
3.41-4.20 & \text { Very Satisfa } \\
2.61-3.40 & \text { Satisfactory } \\
1.81-2.60 & \text { Fair } \\
1.00-1.80 & \text { Poor }\end{array}$ & & & \\
\hline
\end{tabular}

\subsection{Status of 7E Model Inquiry-Based Approach}

Table 2 shows the status of the teacher in her use of the 7E Model Inquiry-Based approach while teaching Science. All items are rated outstanding. The teacher received an overall average of 4.75 which is interpreted as outstanding. This means that the teacher prepares and executes well in teaching using 7E Model Inquiry-Based approach. The sd which is 0.47 shows that the perception or rating of the students are homogenous.

Table 2. The teacher's status using the 7E model inquiry-based teaching approach

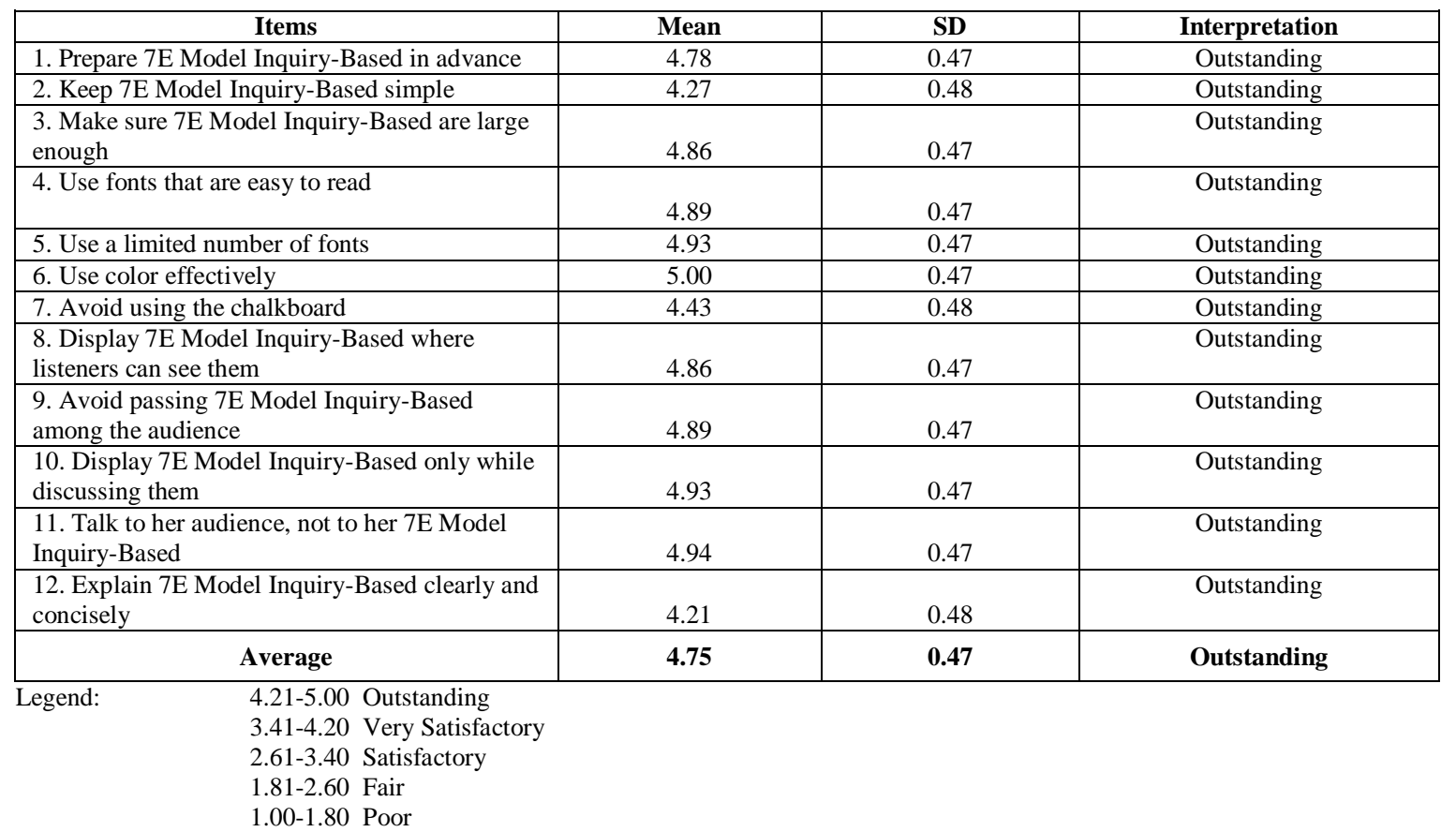

\subsection{Academic Achievement of the Learners}

The table below shows the result of the spot test in Science after handling two sets of learners, each having thirty-five individuals. The two groups are separated according to class which was grouped heterogeneously. Therefore, the element of difference in mental ability is already taken out or removed from the contributing factor. 
The group who has undergone traditional instruction approach got a mean score of 8.63, interpreted as satisfactory, with an sd of 1.78. The group who has undergone 7E Model Inquiry-Based approach got a mean score of 10.77, interpreted as very satisfactory, with an sd of 2.44. The sd of Traditional instruction approach 7E Model Inquiry-Based approach which is lower than the sd of 7E Model Inquiry-Based approach shows that the scores of students who undergone Traditional instruction approach are nearer to each other than the scores of the students who have undergone 7E Model Inquiry-Based approach.

Table 3. Academic achievement of learners as reflected in their spot tests on the science topic "female reproductive system"

\begin{tabular}{|c|c|c|c|c|}
\hline Teaching Tool & $\begin{array}{l}\text { Number of } \\
\text { Students }\end{array}$ & Mean & SD & Interpretation \\
\hline Traditional Instruction Approach & 35 & 8.63 & 1.78 & Satisfactory \\
\hline 7E Model Inquiry-Based & 35 & 10.77 & 2.44 & Very Satisfactory \\
\hline Average & & 9.70 & 2.11 & Satisfactory \\
\hline $\begin{array}{l}13.00-15 \\
10.00-12.99 \\
7.00-9.99 \\
4.00-6.99 \\
1.00-3.99\end{array}$ & $\begin{array}{l}\text { tstanding } \\
\text { ry Satisfactory } \\
\text { isfactory } \\
\text { ir } \\
\text { or }\end{array}$ & & & \\
\hline
\end{tabular}

\subsection{Significant Difference Between Academic Achievement Using the Two Teaching Approaches'}

Table 4. T-test of academic achievement of students who have undergone two teaching tools

\begin{tabular}{|l|l|l|l|l|l|l|}
\hline \multicolumn{1}{|c|}{ Teaching Tool } & Mean & SD & T-crit & T-comp & Decision & Interpretation \\
\hline Traditional Outlining & 8.63 & 1.78 & & & \\
& 7E Model Inquiry-Based & 10.77 & 2.44 & \multirow{2}{*}{1.20} & \multirow{2}{*}{ Reject $\mathrm{H}_{\mathrm{o}}$} & \\
& & & & & & \\
\hline
\end{tabular}

$\alpha=0.05$

The table below shows the result of the t-test of significant difference of academic achievement. The critical value, or the value from the table is 1.20 , while the computed value is 4.20 . This is using alpha 0.05 , that means, 95\% accuracy. Since the critical value is lower than the computed value, the null hypothesis is rejected. This means that there is significant difference between the academic achievement of students who have undergone two kinds of teaching tools. Those who have undergone 7E Model Inquiry-Based approach results into better academic achievement than those who have undergone traditional instruction approach.

This result can easily be explained with some factors relating to $7 \mathrm{E}$ Model Inquiry-Based. In $7 \mathrm{E}$ Model Inquiry-Based Approach, the relations of every variables or elements are easily shown. Learners learn more when the visualization is not just vertical or horizontal, but in a way that concepts are presented in a meaningful and varied way. 7E Model Inquiry-Based also sticks better in memory than the one presented in outlines because 7E Model Inquiry-Based allow them to explore the ideas and learners were able to describe their progress, and allow them to measure their improvement.

\section{Summary, Conclusion and Recommendation}

This section recaps the important parts of the study by giving the summary, discusses the conclusion, and leaves recommendation to target person or group of persons. 


\subsection{Summary of Findings}

This study came into interest from the researcher because of the emerging need of looking into what is fitted nowadays in terms of having good academic achievement in Science Teaching under the K-12 program. Studies may have been conducted on the good effect of 7E Model Inquiry-Based Approach to student's achievement but none has tested it against traditional instruction approach. Here are the concerns posed at the beginning of the study:

- Status of teaching tools as used in Science (traditional instruction approach and 7E Model InquiryBased Approach);

a. Academic achievement of learners; and

b. Significant difference of academic achievement under two teaching approaches.

- The statistical tools used to deal with the above concerns are the following:

a. Mean and sd for status of teaching approaches

b. Mean and sd for academic achievement of learners; and

c. T-test for significant difference of academic achievement.

- The results using the statistical tools mentioned in the previous page are as follows:

a. The learners rated their teacher's use of traditional instruction approach 'outstanding' based from the overall average of 4.47 and sd of 0.48 . On the other hand, they rated their teacher's use of 7E Model Inquiry-based approach also 'outstanding' based from the overall average of 4.75 and sd of 0.47 ;

b. The first class of students (35 learners) got an average of 8.63 in a spot test, interpreted as satisfactory, with an sd of 1.78. The second class or students (35 learners) got an average of 10.77, interpreted as very satisfactory, with an sd of 2.44. Overall, the 70 learners got an average of 9.70 , interpreted as satisfactory, with an sd of 2.11 ; and

c. The critical value for a t-test with alpha 0.05 is 1.20 . The computed value is 4.20 . Since the critical value is lower than the computed value, the null hypothesis is rejected.

\subsection{Conclusion}

Based from the result of findings, the conclusion is made:

There is a significant difference between the academic achievement of learners who have undergone traditional instruction approach and academic achievement of learners who have undergone 7E model inquiry-based approach. The students perform better when 7E model inquiry-based approach is used rather than traditional instruction approach.

\subsection{Recommendation}

Considering the result obtained from this study, the following recommendations are given to target persons:

- That Science Teachers make use of 7E model inquiry-based approach more than traditional instruction approach. Though this would take more effort to do, it would give better academic achievement for learners;

- That Science Coordinators Update Science Teachers on the how-and-why of 7E model inquirybased approach so that Science Teachers would be more effective in using that teaching approach;

- That School Heads continue to promote the use of 7E model inquiry-based approach not only for Science subject but to all subjects (if applicable); 
- That the Department Education (on district or division level) raise concerns, seminars and workshops on the effective use of $7 \mathrm{E}$ model inquiry-based approach so that educational status can be sustained or even attain higher heights.

\section{References}

Acar Sesen, B., \& Tarhan L. (2013). Inquiry-based laboratory activities in electrochemistry: High school students' achievements and attitudes. Research in Science Education, 43(1), 413-435.

Acisli, S., \& Turgut, U. (2011). The examination of the influence of the materials generated in compliance with 5E learning model on physics laboratory application. International Online Journal of Educational Science, 3(2), 562-593.

Acisli, S. (2010). The examination of the influence of the materials generated in compliance with 5e learning model on physics laboratory application (Unpublished doctoral thesis), Ataturk University, Turkey

Advances in Social Science, Education and Humanities Research, volume 277International Conference on Science, Technology, Education, Arts, Culture and Humanity (STEACH 2018)

Akerson, V. L., Townsend, S., Donnelly, L. A., Hanson D. L., Tira, P., \& White, O. (2009). Scientific Modelling for Inquiring Teachers Network (SMIT'N): The Influence on Elementary Teachers' Views of Nature of Science, Inquiry, and Modelling, Journal of Science Teacher Education, 20, 21-40 DOI 10.1007/s10972-008-9116-5.

Apriyani, Penerapan Model Learning Cycle 5E dalam Upaya Meningkatkan Kemampuan Pemecahan Masalah Matematika Siswa SMPN 2 Sandeng Kelas VIII pada Pokok Bahasan Prisma dan Limas. Tersedia, 2010

Balta, N., \& Sarac, H. (2016). The effect of 7E learning cycle on learning in science teaching: A meta-analysis study. European Journal of Educational Research, 5(2), 61-72.

Blanchard, M. R., Southerland, S. A., Osborne, J. W., Sampson, V. D., Annetta, L. A., \& Granger, E. M. (2010). Is inquiry possible in light of accountability? A quantitative comparison of the relative effectiveness of guided inquiry and verification laboratory instruction. Science Education, 94(4), 577-616.

Bransford, J.D., A.L. Brown, and R.R. Cocking, eds. (2000). How People Learn. Washington, D.C.: National Academy Press

Bevevino, M., Dengel, J. and Adams, K. (1999), Constructivist Theory in the Classroom, Constructivist Theory In the Classroom

Bianchi, H., \& Bell, R. (2008). The many levels of inquiry. Science \& Children, 46(2), 26-29.

Bulbul, y.(2010).Effects of 7E learning cycle model accompanied with computer animations on Understanding of diffusion and osmosis concepts. Middle East Technical University.

Bybee, R., Taylor J., Gardner A., Scotter, P., Powell, J., Westbrook, A., \& Landes, N., (2006). The BSCS 5E Instructional Model: Origins, Effectives, and Applications.Executive Summary, BSCS, Colorado Springs, CO.

Chang, H., Chen, C. C., Guo, G., Cheng, Y., Lin, C., \& Jen, T. (2011). The development of a competence scale for learning science: Inquiry and communication. International Journal of Science \& Mathematics Education, 9(5), 1213-1233.

Capobianco, B. M., \& Feldman, A. (2010). Repositioning teacher action research in science teacher education. Journal of Science Teacher Education, 21(8), 909-915.

Cavallo, A.M.L. \& Laubach, T.A. (2001). Students' Science Perceptions and Enrollment Decisions in Differing Learning Cycle Classrooms. Journal of Research in Science Teaching, 38(9), 1029-1062..

Freedman, M. P. (1997). Relationship among laboratory instruction, attitude toward science, and achievement in science knowledge. Journal of Research in Science Teaching, 34(4), 343-357.

Gül Kaleli Y. Imaza, Elif Ertemb, Salih Çepnib, "The effect of the material based on the 7E model on the fourth grade students' comprehension skill about fraction concepts", Procedia Social and Behavioral Sciences 2, 2010, pp. 1405-1409

Gunes, B., Akyuz, O., Saçlı, O.A., Mutus, H., Ates, S., Eryilmaz \& Ulutas, S. (2011). Ministry of Education Board of Curriculum of Physics, Ankara.

Gurbuz, F. (2012). The effect 7e model on academic achievement and retention of knowledge in the unit of "Electricity in our Life" in 6th grade science and technology (Unpublished doctoral thesis), Ataturk University, Turkey.

Hirca, N. (2008). An investigation of effects on conceptual change of developed materials based on 5E model in unit "work, power and energy" (Unpublished doctoral thesis), Ataturk University, Turkey

Kanli, U. (2007). The effects of a laboratory based on the 7e model with verification laboratory approach on students? development of science process skills and conceptual achievement (Unpublished doctoral thesis), Gazi University, Turkey.

Kalaycı, S., Kayıs, A., Antalyali, O., Ucar, N., Demirgil, H., İsler, D \& Cicek, E. (2007). Multivariate statistical techniques, Ankara: Asil Publishing.

Lord, Thomas R. 1999. A Comparison Between Traditional and Constructivist Teaching in Environmental Science. Journal of Environmental Education. Vol. 30, No. 3:22-28.

Özalp, I. (2006). A study of implementing the technique or caricature in science environmental education. (Master thesis). Celal Bayar University, Manisa, Turkey.

Özbek, G., Çelik, H., Ulukok, Ş., \& Sarı, U. (2012). 5E ve 7E Öğretim Modellerinin Fen Okur-Yazarlığı Üzerine Etkisi [5e and 7e instructional models effect on science literacy]. Journal of Research in Education $\quad$ and Teaching, 1(3), $183-194$. 
Ozsevgec, T. (2007). Determining effectiveness of guided materials about force and motion unit based on the 5E model for elementary students (Unpublished doctoral thesis), Karadeniz Technical University, Turkey

Sandoval, W. A., \& Reiser, B. J.(2004). Explanation-driven inquiry: Integrating conceptual and epistemic scaffolds for scientific inquiry. Science Education, 88, 342-375.

Savas, B. (2009). Constructivist learning. A. Kaya (Ed). Educational Psychology (s.411-434). Ankara: Pegem Akademi.

S. m. Iskandar, Strategi Pembelajaran Kontruktivistik dalam Kimia. Malang; Penerbit UM, 2005

Secker.v.c(2002)Effects of Inquiry-Based Teacher Practices on Science Excellence and Equity .The Journal of Educational Research January/February 2002 [Vol. 95(No. 3)]

Stofflett, Rene T. (1998). Putting Constructivist Teaching into Practice in Undergraduate Introductory Science. Electronic Journal of Science Education, Vol. 3, No. 2.

The College Board. (2006a). AP Physics B: Free response questions [PDF file]. Retrieved from http://apcentral.collegeboard.com/apc/public/repository /_ap06_frq_physicsb_51782.pdf

The Effect of 7E Learning Cycle on Learning in Science Teaching: A meta-Analysis Study, Nuri Bata 2016 in European Educational Research Journal 5(2):61-72

The Effect of 7E Model on Conceptual Success of Students in The Unit of Electromagnetism European J of Physics Education Volume 7 Issue 3 1309-7202 Turgut et al. Umit Turgut1 Alp Colak2 Riza Salar3

The Effectiveness of 7E Learning Model to Improve Scientific Literacy, Fitri Mur Fatimah Vaughn C. Vick, 2018, THE EFFECT OF 7E MODEL INQUIRY-BASED LABS ON STUDENT ACHIEVEMENT IN ADVANCED PLACEMENT PHYSICS: AN ACTION RESEARCH STUDY 4-5

Yore, Larry D. 2001. What is Meant by Constructivist Science Teaching and Will the Science Education Community Stay the Course for Meaningful Reform? Electronic Journal of Science Education, Vol. 5, No. 